\title{
Should We be More “Open” About Publishing Research?
}

\author{
Allahbadia Gautam N.
}

Published online: 7 October 2014

(C) Federation of Obstetric \& Gynecological Societies of India 2014

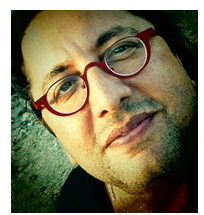

\begin{abstract}
About the Author
Gautam N Allahbadia is the Editor-in-chief of the Journal of Obstetrics \& Gynecology of India as well as the IVF Lite (Journal of Minimal Stimulation IVF). He is the Medical Director of Rotunda, The Center for Human Reproduction, the world-renowned fertility clinic at Bandra, Mumbai, India as also the New Hope IVF Clinic at Sharjah, UAE. He is a noted world authority on Ultrasound-guided Embryo Transfers and one of the pioneers in Third Party Reproduction in South-East Asia. Dr. Allahbadia was responsible for India's first trans-ethnic surrogate pregnancy involving a Chinese couple's baby delivered by an unrelated Indian surrogate mother. He has over 100 peer-reviewed publications to his credit and is on the Editorial Board of several International Journals. Throughout his career, Dr. Allahbadia has been instrumental in developing new fertility enhancing protocols and propagating the use of Ultrasound in Embryo Transfer procedures. You can read more about his work at www.gautamallahbadia.com.
\end{abstract}

\section{Introduction}

Dr Spock is a brilliant young vascular surgeon who is up for promotion next year. The chair of surgery has warned him that he needs to increase his list of publications to assure passage. He has recently had a paper reviewed by one of the top journals in his specialty, Journal X-special, with several suggestions for revision. He received an e-mail request for manuscript submission from a newly minted, open access, Journal of Vascular Disease Therapy, which promises a quick and likely favorable response for a fee. What should be done? A. Send the paper to another peer-reviewed journal with the suggested revisions. B. Resubmit the paper to Journal X-special. C. Submit to the online journal as is to save time. D. Submit to the

Allahbadia G. N. ( $₫)$, Editor-in-chief

Rotunda - The Center For Human Reproduction, Bandra,

Mumbai, India

e-mail: ivfwaladoc@gmail.com online journal and another regular journal. E. Look for another job. These were the questions posed by Jones \& McCullough in their excellent recent publication that discussed corruption in publication research [1]. Is openaccess publishing the wave of the future in science?

Open access (OA) means unrestricted free online access to peer-reviewed scholarly research. Open access is primarily intended for scholarly journal articles, but is also provided for a growing number of theses, book chapters, and scholarly monographs [2-4]. The OA movement had its official start in 2002 with the establishment of the Budapest Open-Access Initiative [2]. Public access to the World Wide Web became widespread in the late 1990s and early 2000s. The low-cost distribution technology has fueled the open-access movement. Conventional non-openaccess journals cover publishing costs through access tolls such as subscriptions, site licenses, or pay-per-view [2]. Some non-open-access journals provide open access after an embargo period of 6-12 months or longer [3]. 
The movement for open access to science seeks to achieve unrestricted and free access to academic publications on the Internet. To this end, two mechanisms have been established: the gold road, in which scientific journals are openly accessible, and the green road, in which publications are self-archived in repositories. The publication of the Finch Report in 2012, advocating exclusively the adoption of the gold road, generated a debate as to whether either of the two options should be prioritized [5]. The recommendations of the Finch Report stirred controversy among academicians specialized in open-access issues, who felt that the role played by repositories was not adequately considered and because the green road places the burden of publishing costs basically on authors. The Finch Report's conclusions are compatible with the characteristics of science communication in the UK and they could surely also be applied to the (few) countries with a powerful publishing industry and substantial research funding.

In Spain, both the current national legislation and the existing rules at universities largely advocate the green road. This is directly related to the structure of scientific communication in Spain, where many journals have little commercial significance, the system of charging a fee to authors has not been adopted, and there is a good repository infrastructure. As for open-access policies, the performance of the scientific communication system in each country should be carefully analyzed to determine the most suitable open-access strategy [5].

The premises behind open-access publishing are that there are viable funding models to maintain traditional peer review standards of quality while also making OA selfsufficient. The challenge is to establish a sustainable financial business model that will permit the use of digital technology but yet not endanger the decades-old traditional publication model and peer review system. Rather than making journal articles accessible through a subscription business model, all academic publications could be made free to read and published with some other cost-recovery models, such as publication charges, subsidies, or charging subscriptions only for the print edition, with the online edition gratis or "free to read" [6-8].

The idealists for the open-access movement are seeking open access to the literature but also to the data that constitute the research within the manuscript [9]. The openaccess movement is maturing and must be embraced in some format. Authors seem to be slower in adopting open access than the idealists in the movement [6-9].

\section{Discussion}

The OA movement has accordingly been working to give everyone a greater awareness of the serious social problems caused by restricting access to academic research as well as the serious economic challenges for the future of academic publishing $[10,11]$. The intended audience of research articles is usually other researchers. Open access helps researchers as readers by opening up access to articles that their libraries do not subscribe to. One of the great beneficiaries of open access may be users in developing countries, where currently some universities find it difficult to pay for subscriptions required to access the most recent journals [12-14]. Some schemes exist for providing subscription scientific publications to those affiliated to institutions in developing countries at little or no cost.

The idea that peer-reviewed OA publication leads to higher rates of citation has been put forth and shown to be true in several publications $[15,16]$. This is a significant benefit to authors and is in addition to another relatively less obvious but highly critical component of the OA charter, i.e., retention of the copyright by the authors in the public domain [15]. The main reason authors make their articles openly accessible is to maximize their research impact.

In a recent study, Frisch et al. [16] analyzed the citation rates of $\mathrm{OA}$ and traditional non-OA publications. They compared the citation patterns for authors who had published in both OA and traditional non-OA peer-reviewed scientific journals. The rate of citation and time-adjusted citation quotient were higher for $\mathrm{OA}$ in the group where abstracts were included ( $P<0.05$ for both). The rates were also slightly higher for OA than non-OA when the meeting abstracts were excluded. They observed that for the same author, the publications in the OA journal attained a higher rate of citation than the publications in the traditional nonOA journals over a 5-year period (2007-2011). Overall, the rates of citation for $\mathrm{OA}$ and non-OA were slightly higher to comparable [16]. A growing number of studies have confirmed, with varying degrees of methodological rigor, that an open-access article is more likely to be used and cited than one behind subscription barriers [15-17].

Gasparyan et al. [18] conducted searches through PubMed to retrieve errata, duplicate, and retracted publications (as of January 30, 2014). Their analysis found 2,597 correction items. A striking increase in the number of corrections appeared in 2013, which is mainly due to 871 $(85.3 \%)$ corrections from PLOS One. The number of duplicate publications was 1,086 . Articles frequently published in duplicate were reviews $(15.6 \%)$, original studies $(12.6 \%)$, and case reports $(7.6 \%)$, whereas top three retracted articles were original studies $(10.1 \%)$, randomized trials $(8.8 \%)$, and reviews $(7 \%)$. A strong association existed between the total number of publications across countries and duplicate ( $\mathrm{rs}=0.86, P<0.0001$ ) and retracted items ( $\mathrm{rs}=0.812, P<0.0001)$. A similar trend was found between country-based h-index values and 
duplicate and retracted publications. The study suggests that the intensified self-correction in biomedicine is due to the attention of readers and authors, who spot errors in their hub of evidence-based information [18]. What we need to understand is that it is only because of digitization and open access that there is the staggering increase in correction notices and retractions.

Some open-access journals are believed to have devaluated the highly respected image of the scientific journal. This has been, it is claimed, verified [19]. Two recent "scams" —one recently published in Science-highlight the urgency of addressing the issues raised by OA publication so that OA does not lose its credibility just as it begins to gather substantial momentum [20-22]. Yet the failure of the mainstream journal Science to publish a report, which Science published, was itself a perfect example of "bad science" [19-22]. $100 \%$ of the controls (normal non-open-access journals; in the present study, this was Science) accepted the "bait" paper for publication, while in the experimental group, only about $60 \%$ (openaccess journals) accepted the bait paper for publication [21, 23]. The conclusion was that, with respect to non-open access and open access, the probability of accepting pseudoscience was well in favor of this being done by a non-open-access journal [23].

Scholars are paid by research funders and/or their universities to do research; the published article is the report of the work they have done, rather than an item for commercial gain. The more the article is used, cited, applied, and built upon, the better for research as well as for the researcher's career [24].

Open access can be provided by traditional publishers, who may publish open access as well as subscription-based journals, or open-access publishers such as Public Library of Science (PLOS), who publish only open-access journals. An open-access journal may or may not charge a publishing fee; open-access publishing does not necessarily mean that the author has to pay. When open-access journals do charge processing fees, it is the author's employer or research funder who typically pays the fee, not the individual author, and many journals will waive the fee in cases of financial hardship, or for authors in less-developed countries [25, 26]. Some no-fee journals have institutional subsidies. Examples of open-access publishers are BioMed Central and the Public Library of Science.

The "article processing charges" which are often used for open-access journals shift the burden of payment from readers to authors, which create a new set of concerns. One concern is that if a publisher makes a profit from accepting papers, it has an incentive to accept anything submitted, rather than selecting and rejecting articles based on quality [27-29].

The scientific community carries out peer review-a major part of scholarly publishing-for free, yet subscription-journal publishers charge billions of dollars per year for scientists to read the final product. But publishers of subscription journals insist that such views are misguided-born of a failure to appreciate the value they add to the papers they publish, and to the research community as a whole. They say that their commercial operations are in fact quite efficient, so that if a switch to openaccess publishing led scientists to drive down fees by choosing cheaper journals, it would undermine important values such as editorial quality [21, 26].

Data from the consulting firm Outsell in Burlingame, California suggest that the science-publishing industry generated $\$ 9.4$ billion in revenue in 2011 and published around 1.8 million English-language articles-an average revenue per article of roughly $\$ 5,000$ [17]. Analysts estimate profit margins at $20-30 \%$ for the industry, so the average cost to the publisher of producing an article is likely to be around $\$ 3,500-4,000$. Most open-access publishers charge fees that are much lower than the industry's average revenue, although there is a wide scatter between journals. The largest open-access publishers-BioMed Central and PLoS-charge \$1,350-2,250 to publish peerreviewed articles in many of their journals. Outsell estimates that the average per-article charge for open-access publishers in 2011 was $\$ 660$ [17].

But a total conversion will be slow in coming, because scientists still have every economic incentive to submit their papers to high-prestige subscription journals. The subscriptions tend to be paid for by campus libraries, and few individual scientists see the costs directly. From their perspective, publication is effectively free.

Of course, many researchers have been swayed by the ethical argument, made so forcefully by open-access advocates, that publicly funded research should be freely available to everyone.

Although many see a switch to open access as inevitable, the transition will be gradual. In the United Kingdom, portions of grant money are being spent on open access, but libraries still need to pay for research published in subscription journals. In the meantime, some scientists are urging their colleagues to deposit any manuscripts they publish in subscription journals in free online repositories. More than $60 \%$ of journals already allow authors to selfarchive content that has been peer-reviewed and accepted for publication. Most of the others ask authors to wait for a time (say, a year), before they archive their papers. However, the vast majority of authors do not self-archive their manuscripts unless prompted by university or funder mandates.

In 2014, the vast majority of published biomedical research is still hidden behind pay-walls rather than open access. For more than a decade, similar restrictions over other digitally available content have engendered illegal 
activity. Music file sharing became rampant in the late 1990s as communities formed around new ways to share. The frequency and scale of cyber-attacks against commercial and government interests have increased dramatically. Massive troves of classified government documents have become public through the actions of a few. Yet we have not seen significant growth in the illegal sharing of peer-reviewed academic articles. Should we truly expect that biomedical publishing is somehow at less risk than other content-generating industries? What of the larger threat-a "Biblioleaks" event-a database breach and public leak of the substantial archives of biomedical literature? [30] As the expectation that all researches should be available to everyone becomes the norm for a younger generation of researchers and the broader community, the motivations for such a leak are likely to grow [30].

\section{Conclusions}

More government and funding agencies are mandating open access to their funded research. The goal of the OA movement is to remove access barriers, accelerate research, and thereby achieve its broader mission of promoting global welfare. The OA movement has made swift progress over the past decade, but has introduced a disruptive change into the scientific community [31]. The early stages of OA publishing have raised strong apprehensions, such as reliability concerns and the emergence of so-called predatory journals [32].

\section{References}

1. Jones JW, McCullough LB. Publishing corruption discussion: predatory journalism. J Vasc Surg. 2014;59(2):536-7. doi: 10.1016/j.jvs.2013.12.001.

2. Petersen E. Open access publishing. Int $\mathrm{J}$ Infect Dis. 2014;25:150-1. doi:10.1016/j.ijid.2014.06.002.

3. Eglen S. Open access: sharing your data is easier than you think. Nature. 2014;510(7505):340. doi:10.1038/510340c.

4. Pierce GN. Is open-access publishing the wave of the future in science? Can J Physiol Pharmacol. 2014;92(5): iii. doi: 10.1139/cjpp-2014-0077

5. Abadal E. Gold or green: the debate on open access policies. Int Microbiol. 2013;16(3):199-203.

6. Liesegang TJ. The continued movement for open access to peerreviewed literature. Am J Ophthalmol. 2013;156(3):423-32. doi: 10.1016/j.ajo.2013.04.033.

7. Goodhill GJ. Open access: practical costs of data sharing. Nature. 2014;509(7498):33. doi:10.1038/509033b.

8. Wiwanitkit V, Qu S. Open access publication, journal policy, and scientific community. Am J Med. 2014;127(5):e13. doi: 10.1016/j.amjmed.2013.12.025.
9. Delbeke D. Open access. J Nucl Med. 2014;55(3):22A.

10. Chatterjee P, Biswas T, Mishra V. Open access: the changing face of scientific publishing. J Family Med Prim Care. 2013;2(2):128-30. doi:10.4103/2249-4863.117400.

11. Munroe R. The rise of open access. Science. 2013;342(6154): 58-9. doi:10.1126/science.342.6154.58.

12. Sau K. Facts about journal publishing in open access policy. Indian J Med Res. 2013;138(6):1029-30.

13. Dai N, Xu D, Zhong X, et al. Publishing in open access era: focus on respiratory journals. J Thorac Dis. 2014;6(5):564-7. doi: 10.3978/j.issn.2072-1439.2014.03.18.

14. Matheka DM, Nderitu J, Mutonga D, et al. Open access: academic publishing and its implications for knowledge equity in Kenya. Global Health. 2014;9(10):26. doi:10.1186/17448603-10-26.

15. Kahn M. Sharing your scholarship while avoiding the predators: guidelines for medical physicists interested in open access publishing. Med Phys. 2014;41(7):070401. doi:10.1118/1.4883836.

16. Frisch NK, Nathan R, Ahmed YK, et al. Authors attain comparable or slightly higher rates of citation publishing in an open access journal (CytoJournal) compared to traditional cytopathology journals - A five year (2007-2011) experience. Cytojournal. 2014;11:10. doi: 10.4103/1742-6413.131739

17. Noorden RV. Open access: the true cost of science publishing. Nature. 2013;495:426-9. doi:10.1038/495426a.

18. Gasparyan AY, Ayvazyan L, Akazhanov NA, et al. Self-correction in biomedical publications and the scientific impact. Croat Med J. 2014;55(1):61-72.

19. van Meerbeek B, Roulet JF. Open-access journals: a scientific thriller. J Adhes Dent. 2013;15(6):503-4. doi:10.3290/j.jad. a31107.

20. Balon R. Perilous terra incognita-open-access journals. Acad Psychiatry. 2014;38(2):221-3. doi:10.1007/s40596-014-0059-1.

21. Tatalović M. What has Science's open-access sting taught us about the quality of peer review? Bosn J Basic Med Sci. 2013; 13(4):209-11.

22. Boumil MM, Salem DN. In and out: open access publishing in scientific journals. Qual Manag Health Care. 2014;23(3):133-7. doi:10.1097/QMH.0000000000000035.

23. Pavlovic D, Usichenko TI, Lehmann C. The last bite was deadlyabout responsibility in scientific publishing. Clin Hemorheol Microcirc. 2014;57(2):95-9. doi:10.3233/CH-141820.

24. Barić H, Polšek D, Andrijašević L, et al. Open access - is this the future of medical publishing? Croat Med J. 2013;54(4):315-8.

25. Gasparyan AY, Ayvazyan L, Kitas GD. Open access: changing global science publishing. Croat Med J. 2013;54(4):403-6.

26. Dugas M. Time for open access to all medical documentation forms.BMJ. 2013;347:f5824. doi:10.1136/bmj.f5824

27. Agrawal AA. Four more reasons to be skeptical of open-access publishing. Trends Plant Sci. 2014;19(3):133. doi:10.1016/ j.tplants.2014.01.005

28. Leopold SS. Paying to publish-what is open access and why is it important? Clin Orthop Relat Res. 2014;472(6):1665-6. doi: 10.1007/s11999-014-3615-9.

29. Xu LL, Chau AM. Caveat emptor: the corruption of open access scientific publishing. Med J Aust. 2014;200(7):386-8.

30. Dunn AG, Coiera E, Mandl KD. Is biblioleaks inevitable? J Med Internet Res. 2014;16(4):e112. doi:10.2196/jmir.3331.

31. Viale PH. Publishing in open-access journals: potential pitfalls. J Adv Pract Oncol. 2013;4(4):195-6.

32. Knoll JL. Open access journals and forensic publishing. J Am Acad Psychiatry Law. 2014;42(3):315-21. 